This item was submitted to Loughborough's Research Repository by the author.

Items in Figshare are protected by copyright, with all rights reserved, unless otherwise indicated.

\title{
How should I respond to them? An emergent categorization of responses to interpersonally communicated stereotypes
}

\section{PLEASE CITE THE PUBLISHED VERSION}

http://dx.doi.org/10.1080/17475759.2014.1001994

\section{PUBLISHER}

Taylor \& Francis (@ World Communication Association)

\section{VERSION}

AM (Accepted Manuscript)

\section{PUBLISHER STATEMENT}

This work is made available according to the conditions of the Creative Commons Attribution-NonCommercialNoDerivatives 4.0 International (CC BY-NC-ND 4.0) licence. Full details of this licence are available at: https://creativecommons.org/licenses/by-nc-nd/4.0/

\section{LICENCE}

CC BY-NC-ND 4.0

\section{REPOSITORY RECORD}

Kurylo, Anastacia, and Jessica Robles. 2019. "How Should I Respond to Them? an Emergent Categorization of Responses to Interpersonally Communicated Stereotypes". figshare. https://hdl.handle.net/2134/20706. 
How should I respond to them?

An Emergent Categorization of Responses to Interpersonally Communicated Stereotypes ${ }^{1}$ Word count: 10,355

${ }^{1}$ Study one is dedicated to Patrick Velez by the first author for his help, patience, and guidance with this project. 
Political correctness defines stereotypes as inappropriate to communicate. However, responses that interpersonally communicated stereotypes receive in conversation may collaboratively produce a different meaning about the appropriateness of stereotype use. The current research reports two studies that explore responses to interpersonally communicated stereotypes and the role these responses play in the perpetuation of stereotypes. This project contributes qualitative research in intercultural communication that exposes a variety of tolerant response types available to communicators and demonstrates how these responses are managed interactionally in ways that show tolerance for communicated stereotypes.

Key words: Stereotypes; Political Correctness; Face; Discourse/Conversation Analysis; Membership Categorization 


\section{How should I respond to them?}

\section{An Emergent Categorization of Responses to Interpersonally Communicated Stereotypes}

Intercultural communication research has taken various approaches to understanding the role of cultural stereotypes and prejudice in communication, and how attitudes toward cultural difference can affect communication willingness, outcomes, and conflict (e.g., Mertins \& Baus, 2010; Ramasubramanian, 2010; Ting-Toomey, 2007). As a country with a long history of immigration and multiculturalism, the U.S. has faced important intercultural challenges, including the problems that stereotypes, prejudice, racism, and discrimination pose for minorities and co-cultures in all spheres of American life - from interpersonal relationships to political movements. An important component of intercultural communication involves the opinions and attitudes of people toward cultural others, and how those stances are formed, supported, challenged, or maintained over time. This paper takes a dual approach to the study of stereotypes as an intercultural communication phenomenon to examine how people respond to stereotypes about present and non-present cultural others in interpersonal conversations. The first approach develops a coding scheme to categorize types of responses based on young people's self-reported reflections on prior conversations in which stereotypes were communicated. The second approach tests the scheme by applying it, through discourse analysis, to actual instances of stereotypes communicated in recordings of naturally-occurring conversation. In doing so, we examine how stereotypes are maintained despite social movements such as political correctness, public intolerance of racism, and celebrations in all sectors (from education to international relations) of diversity and of the value of intercultural communication (Rees, 1993; Thibodaux, 1994; Williams, 1995). Thus, the research presented here has important implications for why barriers to intercultural understanding and communication continue to exist.

This project contributes to research in quantitative, qualitative, and discourse approaches to intercultural communication; investigates specific ways in which stereotypes are formulated and 
communicated in private American conversations; and examines how the communication of stereotypes and responses to stereotypes may serve to perpetuate stereotypes despite political correctness efforts. The two studies are presented side-by-side in order to provide some level of breadth in the case of the first study and some level of depth in the case of the second study to give the reader a more complete picture of how people respond to communicated stereotypes. Presented together, the studies provide different angles from which to view stereotype phenomena, offer etic and emic perspectives on stereotype responses, explore and expose methodological affordances and limitations, and demonstrate methodological convergence.

Stereotypes are defined in a number of ways across the literature, but most scholars describe it as a relationship between a group and some characteristic attributed to that group (e.g., Ottati \& Lee 1996). There are similarities between the scholarly definitions and how non-experts define stereotypes (Kurylo, 2012). ${ }^{2}$ From the 1960's in American culture the political correctness movement, alongside other civil rights efforts, "fostered work in how stereotypes, prejudice, and discrimination could be reduced" (Liberman, Newman, \& Chaiken, 1998, p. 156). Political correctness defines stereotypes as inappropriate ways to communicate that disenfranchise specific groups and contribute to prejudice, discrimination, and -isms (racism, sexism, ageism, etc.). Political correctness helped institutionalize stereotypes as a concept that can be understood outside any single conversation and has become a rationale for the prescription that people avoid communicating stereotypes. Stereotypes communicated by actor Michael Richards on November 20, 2006 and radio personality Don Imus on April 4, 2007 received overwhelmingly negative responses resulting in an informal blacklist of the former and a firing of the latter. Kurylo (2013) argues that the vilification of celebrities who communicate stereotypes plays out in the media as a warning to audiences that stereotypes are "an unsavory practice

\footnotetext{
${ }^{2}$ For a more thorough review of literature on stereotypes see Kurylo (2013).
} 
to be avoided or concealed" in behavior (Bodenhausen \& Macrae, 1996, p. 232; see also Borisoff \& Victor, 1989; Jussim, McCauley, \& Lee, 1995).

According to political correctness, someone communicating a stereotype, celebrity or not, may be confronted with challenges, contradictions, sanctions, and even isolation in response to their inappropriate behavior. If a devaluation of stereotypes due to political correctness were mainstream and post-racism a reality, then one would expect a decrease in communicated stereotypes over time. Yet stereotypes remain resilient and considerable research notes that communication processes facilitate rather than deter consistent inclusions of stereotypes in cultural knowledge (e.g., Condor, 2006; Kenrick, Maner, Butner, Li, Becherk, \& Schaller, 2002; Lyons \& Kashima, 2001; Schaller, Conway, \& Tanchuk, 2002). Stereotypes persist despite western societies' championing of diversity and increasing globalization processes and intercultural contact across the world (Gilbert, 1951; Karlins, Coffman, \& Walters, 1969; Katz \& Braly, 1933). One reason for stereotype perpetuation despite prescriptions to the contrary is that unlike political correctness, which can be discussed abstractly, conversations are guided by social norms.

Goffman (e.g., 1959; 1963a; 1963b) describes extensively the social norms involved in communication and identifies a "rule of behavior that seems to be common in all situations [that is] ... the rule obliging [people] to 'fit in"” (1963b, p. 11). When a stereotype is communicated in interaction, fitting-in can be accomplished "by, for example, avoiding facts about which the other might be touchy, or by showing constraint in raising criticism" (Goffman, 1963a, p. 159). Thus, even if communicated stereotypes are perceived as conversational "gaffes" (Goffman, 1959, p. 209), situational proprieties may influence people to practice civil inattention by not calling them out (Goffman, 1963a). When viewed through Goffman's concept of face, stereotypes in interaction constitute potentially problematic moments in which identity (face) is negotiated. Participants may be caught between a 
societal expectation to be relevant, honest, and politically correct, and a situational impetus toward order, saving one's own and other's face, and achieving interactional goals.

According to Madon et al. (1998) "virtually all of the research studies examining stereotyping in person perception have been experimental laboratory studies" (p. 1305). This sort of research on cultural stereotypes has demonstrated that stereotypes in for example media portrayals influence people's beliefs about and attitudes toward people of different groups (e.g., Ramasubramanian, 2010, 2011) and that stereotypes evolve and persist in different ways across time (e.g., Schaller \& Latané, 1996). Other research indicates some specific reasons why stereotypes persist, including their role in information exchange, storytelling, and coherence (Kashima, 2003; Lyons \& Kashima, 2001; Lyons \& Kashima, 2003). However, these approaches necessarily have limited insights into specific interpersonal situations in which stereotypes are communicated that may inform stereotype maintenance. In particular these experimental and cognitively-focused studies do not address in detail the discursive practices participants deploy in producing and responding to stereotypes. By looking at stereotypes qualitatively in specific situations in which they occur, we offer another angle on this important social issue; by looking at stereotypes shared to and about cultural others, we examine a phenomenon which is an important factor in the formation of intercultural beliefs and intercultural contact.

Walter Lippman (1922/1965) famously defined stereotypes as pictures in the mind. This emphasis on the mind has inadvertently led to a dearth of discussion of stereotypes that extend beyond the mind into conversation (Kurylo, 2012). When stereotypes are communicated in conversation they are no longer individual cognitive processes but are "publicly accessible" (Semin, 2000, p. 603), able to be heard or seen by others. Because communicated stereotypes are publicly accessible, they are part of an ongoing communicative process and can thereafter be responded to in conversation. 
The response a communicated stereotype receives in a conversation constructs the meaning of that stereotype. From a social construction perspective, meaning is not determined by a dictionary but is produced in the ongoing flow of talk through responses received in each turn of a conversation. For example, 'jerk' may be viewed in American culture as a pejorative descriptor. However, that meaning can be modified by conversational partners through their talk. The word 'jerk' responded to with cheerful laughter potentially changes the presumed original meaning from aggressive/derogatory to lighthearted/friendly. How people respond to a stereotype in the micro-context of a specific conversation brings meaning to that stereotype regardless of what meaning exists about stereotypes at the societal macro-level. ${ }^{3}$

Political correctness defines stereotypes as inappropriate to communicate. However, responses stereotypes receive in conversation may collaboratively produce a different meaning about the appropriateness of stereotype use. This alternate meaning may help to explain why stereotypes are perpetuated over time despite societal prescriptions to avoid their use. This article reports two studies that explore responses to interpersonally communicated stereotypes and the role these responses may play in the perpetuation of stereotypes. The first study develops a coding scheme to analyze selfreports of interpersonal situations in which stereotypes were communicated by classifying types of responses to stereotypes. The second study tests the extent to which this coding scheme can also categorize stereotype responses in recorded conversations in which stereotypes were spontaneously communicated. Together, these studies address different methodological and theoretical approaches to stereotype use, and combine these approaches to understand more fully the importance of responses to stereotypes as well as how responses may contribute to stereotype maintenance or change. The following sections describe first study one's, then study two's, analysis and results. The last section reflects on the implications of both of these studies.

\footnotetext{
${ }^{3}$ The research is not intended to nor able to make claims related to the accuracy or inaccuracy of stereotypes in general or in any single stereotype in particular.
} 


\section{Study One}

Study one asks two research questions: how do people respond to stereotypes communicated interpersonally, and in what ways might these responses facilitate stereotypes maintenance? Because of prescriptions against stereotypes, accounts were used to capture these difficult-to-observe events (e.g., Baumeister, Wotman, \& Stillwell, 1993; Hakansson \& Montgomery, 2003; Koenig Kellas \& Manusov, 2003; Rule, Bisanz, \& Kohn, 1985). Accounts are "self-reports about everyday activities" (Buttny, 1993, p. 14). These provide researchers "a critical way of examining not only key actors and events but also cultural conventions and social norms" (Coffey \& Atkinson, 1996, p. 80). Accounts are limited in that they are selective representations of events (Stafford et al., 1987; Stafford \& Daly, 1984). Nonetheless, accounts are useful to study "particularly sensitive" (Coffey \& Atkinson, 1996, p. 56) and potentially face-threatening events (Tracy \& Robles, 2013). Study one analyzes participants’ written accounts of stereotypes communicated in conversations, including intercultural conversations and conversations about cultural others.

\section{Procedure}

After review board approval, narrative accounts describing "the specific details of a first-hand interaction in the last few days in which someone has verbally or nonverbally communicated a stereotype in an interaction with" the participant were solicited via paper instrument from 161 students in communication courses at a large U.S. east coast university. Instructions clarified, "perhaps you are the one who used the stereotype, perhaps you were clearly able to overhear another conversation, or perhaps someone in an interaction with you communicated the stereotype." Stereotypes included those about the participant, about other present participants, or about non-present others. This level of specificity in the instructions was incorporated with italics in order to trigger participants to provide detail in their accounts and to encourage them to report openly about others if they preferred not to 
report openly about themselves. Accounts ranged from one to three pages in length with the mode being two pages.

\section{Participants $^{4}$}

Seventy-five undergraduate students submitted accounts. Twenty-one accounts were dropped from the data set because participants did not follow instructions in potentially consequential ways. ${ }^{5}$ Their anonymous participation was maintained through a removable cover sheet. This produced a $47 \%$ response rate $(N=54)$. Of these, the majority of the stereotypes were communicated verbally $(n=52$; $96 \%)$ and by someone other than the participant $(n=52 ; 96 \%)$. Demographic information, though requested, was provided inconsistently and, consequently, is not discussed.

\section{Coding}

A thematic analysis explored participants' reported responses to interpersonally communicated stereotypes. Thematic analysis in communication research (e.g., Dougherty, 2001; Orbe \& Warren, 2000; Wright, 2000) is a "process for encoding qualitative information" (Boyatzis, 1998, p. vi; see also Strauss \& Corbin, 1998). For purposes of this study, "response" was operationalized as nonverbal/verbal behavior the participant reported communicating in relation to/after a stereotype was communicated but prior to the conversation's end. Responses reported were not coded unless the response was made by the participant so that each account contributed no more than one response to the data.

The coding process involved five steps. First, accounts were coded as involving specific behaviors (e.g., shaking or nodding head, saying yes/no, etc.). Second, accounts were coded with an estimate of the behaviors' meanings based on how the participants characterized them (e.g.,

\footnotetext{
${ }^{4}$ Pseudonyms are used for all participants mentioned in this research. All accounts from participants that are quoted in this paper are reproduced exactly as they were written, including any grammatical errors.

${ }^{5}$ Fourteen of the dropped accounts described cognitive stereotypes that were not communicated. Six described stereotypes that were communicated in interactions that occurred over a year prior to the data collection and were, therefore, not recent. One was not based on a first-hand experience.
} 
disapproval, approval, ignoring, etc.). Third, behaviors/meanings were analyzed and reduced to a finite set of themes representing response types (e.g., reciprocation, challenge, etc.). Fourth, two dimensions that organically represented the complexity of the data emerged. Response theme labels were created using these two dimensions (see Table 1). The first dimension involves the effort of the response, distinguished as active (behavior deviated from participant's neutral state and seemed to require effort) and passive (behavior was closer to participant's neutral state and seemed to require little-to-no effort). The second dimension involves the stance toward the stereotype content and/or communication: neutral, approval, and disapproval. Fifth, the table and themes were used to systematically code the entire set. Each theme was checked against each other theme in a constant comparative method (Glaser \& Strauss, 1967; Strauss \& Corbin, 1998) to determine boundaries, inclusiveness, and representativeness.

To check the coding, a second trained coder coded $100 \%$ of the data. Overall interrater agreement reached $96 \%(\kappa=.69)$ ranging from $92 \%$ to $100 \%$ when assessed individually for most themes. These agreements established reliability across most categories, suggesting the themes were not arbitrary. Interrater agreement was reached good/very good for eight themes $(\kappa=.63-1.00)$, fair/moderate for three themes $(\kappa=.38-.49)$, and did not meet acceptable agreement levels for three themes: Reciprocation, Accuracy, and Active Disapproval. The following paragraphs will discuss the 14 response themes which were coded representing 13 response types which emerged (see table Appendix A) and a no response discussed theme.

Results

No response discussed theme. The no response discussed theme was coded when the participant did not mention how he or she responded to the stereotype. This was coded even if others in the conversation responded to the stereotype. The remaining themes are categorized according to their location at the intersection of the two dimensions. 
Passive neutral. A passive neutral response theme was coded when the response to the stereotype seemed to require little effort and indicated indifference. Responses included silence, shrugging shoulders, and so forth. For example, while at work as a waiter, one employee informs Leonard that "you just got sat a 4-top (table of four) of Canadians, be ready for a bad tip." Leonard states that "Canadians" was used as a less controversial way to reference blacks and that all those present "seemed to be aware" of this meaning. He reports that he "ignored this comment."

Passive approval. A passive approval response theme was coded when a participant's response indicated acceptance and seemed to require little effort. These responses included nodding, smiling, or laughing. For example, at work, Krzysztof was in a meeting with fellow employees and his boss when a discussion of who would work extra shifts began. A white employee communicated his frustration by stating that he is poor and needs the shifts. In response, a fellow employee who is black said, "your white your not supposed to be poor." Krzysztof notes "I just smiled." The movement of making a smile requires minimal effort.

Four additional more specific passive approval themes emerged. Each demonstrates a way to show approval toward a communicated stereotype. In the amicable clarification response theme, responses keep the conversation friendly while providing clarification about a stereotype in a considerate way, as in the spirit of fostering understanding or avoiding embarrassment. Amicable clarification may respond to a stereotype as a sincere inquiry. For example, Siiri was speaking with her friend about an upcoming trip to India. Her friend, who had "traveled to India over the summer" discussed how "India was a very poor and dirty country." In response, Siiri explained the truth about India "in a way she could understand" because Siiri reported that her "friend did not have an malice or hatred in what she said." In this way, the stereotype is constructed as a potentially legitimate and, therefore appropriate, way to think/communicate about a targeted group. 
In the playing around response theme, responses involve joking or humor. Danielle discusses an interaction where she and coworkers are stereotyping each other and she explains that "Both the blonde stereotype and the age stereotype were out of fun and games.” Through playing around about stereotypes, conversational partners construct the stereotype as non-threatening, non-controversial, and as a generally acceptable way to think/communicate about groups.

In the reciprocation response theme, stereotypes are responded to with a form of repayment in like kind. This may be as simple as a participant responding to one stereotype with another stereotype in such a way as to provide a chance for the stereotyper to clarify/develop their opinion. In one account, Ciara, a sorority member, meets a man at a party who discusses his opinion of sorority members. Ciara responds by explaining her opinion. Ciara says she "was not so affected by his reaction" and "we weren't fighting," indicating the stereotype was a reasonable way to think/communicate. This response constructs equality of perspectives by allowing each person to maintain their viewpoints on the stereotype in an unemotional, non-confrontational, and noncontroversial way, even if they disagree.

In the dueling stereotypes response theme, a stereotype is responded to with another stereotype as if in a competition. The metaphor of dueling sees stereotypes as wielded like weapons in a fight. For the dueling stereotypes theme to be coded, the participant must invoke words in reference to his/her response reflecting the metaphor of a duel, competition, or fight. For example, Laura's account was coded this way because her and her brother "were describing who are the worst drivers women or men." This stereotype competition was ended when the participant stated in a frustrated manner [while passing the "bad" male driver who prompted their competition] "I knew it... what more could you expect!". A competition is indicated in that the conversation ends with a clearly articulated winner. With dueling stereotypes the focus of the conversation is on winning the competition while constructing an affirmative position about whether the stereotype is appropriate. 
Passive disapproval. A passive disapproval response theme was coded for responses requiring little effort and indicating non-acceptance. Passive behaviors included silence, head shaking, and so forth, and were only coded if the participant indicated dislike or disapproval. For example, Hugo was in a Blockbuster movie rental store when a stranger approached him and asked if he played football. Hugo attributes the reason for this question to his being a "bigger than average person." Hugo's response to this stereotype that all big men play football demonstrates a passive disapproval response because he "gave him a pretty evil looking glare and proceeded to answer 'No' in a very low tone," which involve little effort to alter his tone of voice, briefly respond, and glare. Hugo reports that the stereotyper understood the disapproval, returning later to apologize "that he didn't mean to be disrespectful."

Active neutral. An active neutral response theme was coded if the response seemed to require effort and demonstrated a neutral stance. A conversation may continue regardless of whether a stereotype was communicated. Thus the stereotype is ignored, indicating neutrality, and the response is active because the participant exerts effort to continue the conversation. For example, when Carlos is asked if he plays basketball by a stranger in a bar, he responds that he "is just a student." His response required effort and ignored that a stereotype was communicated. In his account, Carlos reported that he was aware of the stereotype and "was a little offended by the fact that because I am black I am supposed to play basketball" but "cannot be completely surprised . . because most basketball players are African American." His ability to see two sides of the issue is manifested in his neutral response.

Active approval. An active approval response theme was coded for responses demonstrating agreement with the stereotype. Active approval requires effort and typically an assenting verbal response. For example when her friend cancels dinner plans, Antoinette responds "I was hoping you would say that! I have no money either!” The friend then stereotypes them according to their shared 
religion when she says "we are such cheap Jews" to which Antoinette responds, "I agree." Antoinette provides an effortful response approving the stereotype.

Active disapproval. An active disapproval response theme was coded if the a participant threatens to discipline, condemns, reprimands or disparages the stereotyper. The response suggests a moral, politically correct, or righteous high-ground, and must involve active nonverbal/verbal behavior. For example, when Venla is instructed by her boss to "see if the bathrooms were clean" Venla "decided to stand up for herself" and "ask why none of the boys could do it." The boss responded that she should do it because "it's a women's job." In response Venla "told him that if he didn't give me another job to do that I would tell the head boss that he was being sexist." Because Venla's response calls her boss sexist and threatens to go to a higher authority, her response indicated active disapproval.

Three additional more specific themes emerged under active disapproval. The challenge response theme provides the opportunity for the stereotyper to explain/defend him/herself or retract the stereotype. For example, Victoria was talking with a co-worker who was "rambling" about her boyfriend's roommate whom she described as “very rude, arrogant and very direct like a typical goomba." The participant responded to this description by looking her "right in her eyes and said "you are just continually insulting me right now, you know that right?"” This response suggests that what her coworker was saying was inappropriate and challenges the coworker. The stereotyper "blushed and looked down" indicating, according to the participant, an insincere display of remorse. The challenge theme can construct the stereotype as inappropriate or politically incorrect, but also gives the stereotyper a chance to defend his/her use

The personal defense response theme claims an exception to the stereotype, but does not argue whether the stereotype is accurate for most people. For example, Elin was in a taxi cab when she

\footnotetext{
6 "Goomba" is an East Coast New York dialect slur for an Italian American.
} 
requested the driver to put on some music. Initially he chose a station playing "Latin rhythms" but then looked back to Elin and said "Oh, I'm sorry. . . do you want me to turn to... what is that? Hot 97, where they play Hip-Hop and R\&B?" In response to the stereotype that black people only listen to certain music, Elin says “What? Do you think I have to like Rap, just because I'm black? I hope that's not what you're thinking because I actually love Salsa music for your information.” Elin identifies herself as an exception to the stereotype. The personal defense theme demonstrates disapproval of the communication of the stereotype in this specific conversation because it does not apply to a particular person. This disapproval of the communication of the stereotype using personal defense constructs approval of the stereotype as true in general.

The accuracy discussion response theme argues whether the stereotype can apply to every person. This may involve the participant's views or a general discussion of the stereotype's accuracy. In either case, the participant demonstrates disapproval of the stereotype because the stereotype is not necessarily true. For example, when a coworker finds out that Valerie's ethnic background is part Latino, she is "shocked" that someone who is "so light skinned" is Latino "because she assumed that [a person] MUST be dark-skinned in order to be Latino." Valerie responds by clarifying this stereotype and "inform[s] her that all Hispanics (like all people in general) are born with different hair colors, eye colors and skin tones." Valerie's response specifies reasons why the stereotype is inaccurate across the targeted group and not just when applied to herself. Unlike challenge and personal defense, accuracy discussion engages the stereotype directly to construct the meaning as inappropriate and does not provide an open-ended opportunity to the stereotype to defend him/herself.

\section{Discussion}

The first research question asked how people respond to stereotypes communicated interpersonally. Results of the study demonstrate participants used thirteen techniques to respond to these stereotypes. This is noteworthy. Political correctness prescribes a single aggressive and disapproving way to 
respond to someone who communicates a stereotype. In contrast, the results of study one demonstrate that communicators have at least thirteen response types at their disposal through which to respond to communicated stereotypes. Thus, there is a breadth of response types from which communicators may choose in conversations in which a stereotypes is communicated. Moreover, the majority of these thirteen response types work with stereotypers, not against stereotypes as prescribed by political correctness, to construct tolerance toward communicated stereotypes. Thus, the responses emerging from this study provide an answer to the second research question regarding how responses to communicated stereotypes facilitate stereotype maintenance.

Tolerance for thinking and communicating stereotypes. Responses were tolerant of stereotypes by not drawing attention to the stereotype as an inappropriate way to think or communicate about the targeted group. In particular, response types that intersect at passive neutral, passive approval, active neutral, and active approval demonstrated that stereotypes were a neutral or even acceptable way to think or communicate. . Additionally, even one disapproval theme demonstrated tolerance as well: the challenge theme provided the stereotyper opportunities to account for the stereotype use and, when used, the conversation eventually led to an approval or neutral response. Thus, the following nine response types, of the thirteen which emerged from this study, serve to perpetuate stereotypes within American culture because they demonstrate tolerance for stereotypes,: passive neutral, passive approval, amicable clarification, playing around, dueling stereotypes, reciprocation, active neutral, active approval, and challenge.

Tolerance for thinking stereotypes, not communicating them. Two responses indicate tolerance for thinking stereotypes, but not for the communication of stereotypes: personal defense and passive disapproval. Personal defense treats the stereotype as true and thus appropriate to think but not to communicate if the targeted person is an exception to the stereotype. Passive disapproval minimally indicates disapproval toward stereotype communication, but without raising an objection at the level of 
belief, tolerates the stereotypes as appropriate to think. Those who use these responses may assume they are objecting to stereotypes when instead they may be participating in a construction process whereby the stereotype is constructed as an acceptable way to think but not communicate.

Tolerance for communicating stereotypes, not thinking them. One response indicates tolerance for communicating stereotypes, but not necessarily for thinking stereotypes. Unlike challenge and personal defense, accuracy discussion argues against the essentializing of the stereotype as true without caveat or limitation. In an accuracy discussion response, a communicator attempts to dissolve the absolute of the stereotype into a generalization not applicable to everyone in the group or to an inaccuracy insufficient to generalize at all. Accuracy discussion provides a loophole for tolerance in two ways, however. The accuracy discussion by its very nature tolerates the communication of the stereotype because it is only by it being communicated that it can be discussed. Also, the nature of the response as a discussion leaves open the possibility that the communicator responding to the stereotype may be incorrect and that the stereotype could be found to be accurate depending on how the discussion plays out.

Non-Tolerance. Only one response type demonstrated lack of tolerance for both thinking and communicating stereotypes. Active disapproval aggressively objected to stereotypes, framing them as inappropriate to think or communicate. This response type is in line with what is prescribed by political correctness. However, the results show that communicators have 12 other response types to choose from when responding to a communicated stereotype. ${ }^{7}$ However, no doubt in part because of conversational norms, people have developed other ways to manage stereotypes communicated in their conversations as indicated by the variety of response types that emerged from the data. Twelve of the thirteen response types allow stereotypers to leave a conversation under the impression that stereotypes are appropriate to think, communicate, or both.

\footnotetext{
${ }^{7}$ The results of the study are not intended to or able to speak to the frequency with which response types occurred in the
} data in any generalizable way. 
These results suggest that responses to communicated stereotypes are far from enacting political correctness. Rather, these responses work with the communicated stereotype to construct stereotyeps as tolerable. Because stereotypes when communicated are publicly accessible and because once communicated they are shared within a cultural knowledge base, how they are responded to matters. The twelve response types tolerating stereotypes as either thoughts or communicative messages or both are a mechanism through which stereotypic knowledge is perpetuated within an American cultural knowledge base over time. Specifically, findings suggest that when stereotypes are communicated, stereotypers are not necessarily sanctioned for violating the prescription to avoid communicating stereotypes despite supposed societal pressures toward political correctness.

Regardless of what people want to or think they would say when someone communicates a stereotype, what people actually do in these conversations may be very different. This has implications for how participants construct intercultural meanings, differences, beliefs, and assumptions in ordinary conversation - material they almost certainly draw on in their intercultural encounters.

\section{Limitations}

There are limitations to this study. First, the data rely on a convenience sample of a student population; however, research has demonstrated that different populations including students, experts, and nonexperts have similar definitions of stereotypes (c.f. Kurylo, 2012). Second, responses used in this study were removed from the ongoing flow of talk in order to create a corpus in which each participant contributed no more than one response for analysis, to enable responses to be categorized alongside other responses, and to produce an emergent/saturated categorization scheme. Third, findings were based on self-reports of conversations rather than conversational data. The use of accounts is appropriate given the difficulty of collecting conversational data in which people communicate stereotypes and the need of study one to create a large corpus from which to produce an emergent/saturated categorization them.. To address some of these limitations and test the emergent 
categorization scheme, a second study applied response type categories to conversational data and explored their descriptive power. Specifically, we wanted to see if applying the taxonomy to self-report and situated, naturally-occurring data would yield some methodological convergence and illustrate a deeper analysis of how people respond to stereotypes in everyday life.

\section{Study Two}

Some researchers critique stereotype maintenance research, suggesting the interactional context of communicated stereotypes needs more empirical study (Hamilton \& Sherman, 1994; Ryan, Park, \& Judd, 1996). These contexts are important because "conversation as it takes place in face-to-face interaction occurs within real time constraints. . [and] it is a production with a social end, which requires synchronization with another's comprehension” (Semin, 2000, p. 597; see also Haslam, Turner, Oakes, Reynolds, \& Doosje, 2002; Jussim, McCauley, \& Lee, 1995; Ottati \& Lee, 1996). Looking closely at conversations in which stereotypes are communicated provided the opportunity for initial analyses applying the stereotype response categorization to naturally-occurring talk.

\subsection{Procedure and Participants}

The following examples of communicated stereotypes were transcribed from six 30-minute to two-hour audio-and-video recordings among young adults in California and New England. These were gathered between 2004 and 2013 as part of a larger research project and a larger (50+ hour) corpus, including (1) data created for non-research purposes which was donated for research, (2) data originally created for student research which was later donated for research, and (3) data which was gathered for research. All data were originally analyzed in research on moral issues in interpersonal communication (second author's dissertation).

Across the six recordings examined for this paper's project, nine conversations were pulled and out among those, 14 instances of stereotypes were collected. Conversations were defined as sequences of acts revolving around a focal topic; instances presented here may include just a portion of a 
conversation in the interest of space. All the recordings feature conversations among pairs or small groups of friends or friendly acquaintances/roommates. ${ }^{8}$ Each instance of communicated stereotype(s) (plural if multiple stereotypes mentioned in one-two proximal utterances) was analyzed to see if responses to the stereotype aligned with the 13 response types from study one; of those, eight examples are presented in the results section. The conversations examined here include some uses of stereotypes toward present participants, but most involve stereotypes about non-present others. Therefore, the data feature some interaction between and among people with intercultural differences, but primarily highlight how intercultural difference is formulated in people's talk about cultural others.

\section{Transcription and Analytical Approach}

This discourse analysis uses transcription notations, vocabulary conventions, and empirical perspectives developed in areas of conversation analysis and discursive psychology (e.g., Edwards, 2005; Potter, 2003; Schegloff, 2007b; Sidnell, 2010). These methodological commitments and the nature of the data (as naturally-occurring versus self-reported accounts) demand certain procedures. First, in the self-reported narratives, participants were asked for and named their responses as responses to communicated stereotypes; in naturally-occurring data, that a stereotype has been communicated must be established in analysis with evidence that the recipient of the stereotypeinvoking talk interpreted the utterance as communicating a stereotype.

Second, the empirical standards of conversation analysis require that an analyst's name for what participants are doing must be grounded in participants' actions rather than as an analyst's label applied to the activity. ${ }^{9}$ Thus, rather than taking the response categorization and looking for data where it may occur, the analysis began by analyzing what participants were doing (once "communicating

\footnotetext{
${ }^{8}$ Two of the recordings include the second author (herein JR); both take place in 2008, years prior to this paper's project. ${ }^{9}$ The research does not attempt to argue which stereotypes do or do not exist in any cultural knowledge base and instead takes its cues for what constitutes a stereotype not from the researcher's perspective but rather from 1) the participants talk and response 2) from membership categorization devices that reflect stereotypes in the ways we have described regardless of the content of any single stereotype.
} 
stereotypes" was established as having occurred via demonstrable participant orientation) in response to a communicated stereotype, and then consulting the response-type taxonomy to see if the participants' uptake could be glossed as any of the response types. Instead of accommodating the (generally quantitative) measures of reliability or validity, this approach addresses qualitative standards for triangulation (using different forms of evidence which converge on the same research object), crystallization (offering different perspectives on a phenomenon and acknowledging the subjective and partial nature of any one claim), and disjuncture (acknowledging and accounting for discrepancies and alternative explanations) (Lindlof \& Taylor, 2011).

Third, to maintain the analytic perspective employed, initial identification of a stereotype was based on membership categorization analysis rather than using lay or analyst definitions. According to membership categorization analysis (MCA), the membership categorization device (MCD) explains participants' interpretive procedures for how identity categories are inferred from or associated with particular human actions, and vice versa (Sacks, 1972, 1992; Sacks \& Schegloff, 1979; Stokoe, 2012). In Sacks's (1992) example of "the baby cried, the mommy picked it up" we hear the baby as the baby of the mommy based on our assumption that people in the category "mother" pick up "their baby" when their baby cries, to comfort the baby. Such assumptions comprise implicit cultural knowledge generated by associations between categories of people and their expected actions/behaviors/traits. Though there are numerous disagreements among scholars about how MCDs should be identified or MCA done (see Carlin, 2010; Eglin \& Hester, 2003; Schegloff, 2007a; Watson, 1997), the concept is useful as a first step for determining whether a category of person has been associated with a particular activity, behavior, trait, and so forth. This concept treats a "stereotype" as potentially present when the mention of an activity, behavior, trait, or so forth is associated categorically with a group.

Further evidence for a stereotype depends on the recipient of talk responding as though it were a stereotype. Stereotypes in contemporary society are recognizable to participants as potentially 
questionable or negative in society even if they are produced as if assuming they will be agreed with or received unproblematically by the particular other to which they are delivered. It is part of participants' cultural knowledge that race-related stereotypes are linked to racist discourse, that racist discourse is associated with a racist stance/identity, and that a racist identity is highly undesirable (van Dijk, 1992). Therefore, the production and reception of a member category plus activity/behavior/trait will typically evince some form of care, face-saving strategies, mitigations, and/or disclaimers if the possibility of attributions of stereotyping or racism is present (van Dijk, 1992). A response which actively disagrees with, disaligns from, or displays non-tolerance with a communicated stereotype will construct the stereotype as a violation (from the perspective of society's stance on racism and political correctness). On the other hand, such displays may constitute a face-threat and violation of social interactional norms.

Our analysis of each example unfolds in three parts. First the potential stereotype is identified through MCA when participants employ a category label and link it (often with implicit causality) to a particular activity/trait/behavior. Second, the interpretation of the communicated stereotype is strengthened by a discussion of how conversational recipients respond. Third, this response/uptake is compared to the thirteen response types (passive/active neutral, amicable clarification, playing around, dueling stereotypes, reciprocation, passive/active approval, passive/active disapproval, challenge, personal defense, accuracy discussion) to determine to what extent these types serve as useful glosses of participant uptake in response to possible stereotypes.

Results

The conversation from which the first three examples are excerpted occurs among a small group of six friends who begin the conversation discussing their ethnic backgrounds.

\#1

Dave: I've got German and Irish ['dude॰

Mark: [and ] Japanese (.) [you're Japanese

Matt: [I don't have any Irish, 
Dave: $\quad[\mathrm{a}(\mathrm{h}) \mathrm{nd} \mathrm{J}(\mathrm{h})$ apanese=

Mark: =you're Japanese Dave shut up

Dave: shut u:p man (0.5) I'm only half Japanese

Mark: [you:'re Japanese enough

Matt: [that's still a reason you] can't [drink

Casey?:[((laughs quietly)) ] [heck ] ya

(1.0)

In example \#1, Mark calls Dave "Japanese” following Dave's self-identification as Irish and German. Dave assents that "Japanese" is among his claimable identities, but asserts that he is "only half-Japanese," demonstrating that Mark's comments were hearable as "Japanese is all you are" and suggests his mention of "half" means there is room for other identities. A potential stereotype is invoked when Matt says to Dave "that's still a reason you can't drink," associating the category "Japanese" with the action "can't drink." According to this stereotype Japanese people cannot, are unable to, or should not drink because they cannot "hold their liquor." For an association to be a stereotype it typically involves an overgeneralized or potentially inaccurate association, often with negative undertones or consequences (e.g., face-threats). This is evidenced in how the utterance is produced as "you can't drink" rather than "you have a reason not to drink." Additionally, that most others present are drinking beer throughout the exchange suggests drinking and being able to hold one's liquor is viewed as desirable for this group. Therefore, having one's identity associated with the "weakness" of not being able to drink implicates that the identity may be undesirable, constituting a face-threat.

The response involves two different types. The only person to respond in an active way is initially-silent Casey. Casey's response, “heck yeah,” demonstrates active approval, overtly agreeing with the stereotype. Dave and Mark respond with a brief silence indicating a passive neutral response. In contrast to study one which only took the participant's response into consideration for further analysis, the presence of multiple participants in this conversational data adds other considerations to the identification of response types by allowing analysis of the combined meaning of the responses. 
The neutral response by Dave and Mark plus the one active agreement gives the overall response a stronger sense of approval than would either response on its own. Matt makes no attempt to defend what he has said, further indicating that he sees no need to account for his comment and thus interprets the response to his comment as a form of approval. The next example demonstrates what happens when another participant adds to the association between drinking and identity.

\#2

Mark: [you:'re Japanese enough

Matt: [that's still a reason you] can't [drink

Casey?:[((laughs quietly)) ] [heck ] ya

(1.0)

Mark: $\uparrow k o m[$ banwa

Jim: $\quad[>$ yeah I don't think $<$ ] it's the German or the Irish

Matt \& Jim: ((laugh)) [((laugh))

Mark: $\quad[$ komban $[w a$

Dave: [(izt-)] VAS IZ DAS

((laughter))

Mark: $\uparrow k o m b a n w a$

Dave: das du ka[ff

Mark: $\quad[\mathrm{su}:] \mathrm{mise}: \mathrm{n}$ kombanwa: $=$

Dave: $=$ das $\mathrm{du}$ kaff=

Mark: $=$ o genki dess $[\mathrm{ka}$

JR: $\quad[(($ laughs $))$

After the silence following Casey’s response to Matt's stereotype, Matt says something to Dave in Japanese (albeit mispronounced). Jim contributes by adding credibility to Matt's stereotype of Japanese, offering that Dave's German or Irish identities would not be responsible for the "can't drink" constraint. Jim's acknowledges that Dave has other identities besides Japanese (not admitted by Mark in example \#1). However, this acknowledgement does so in service of reinforcing that Dave can't drink and that the stereotyped association between ethnic identities and drinking alcohol is true.

By removing Dave's being German and Irish as possible reasons for his “can’t drink” status, Jim implies that German and Irish people can drink and contrasts this with Japanese people. The sarcastic/dismissive "Yeah, I don't think" phrasing suggests German and Irish are not being offered as a neutral contrast to Japanese simply because those are Dave's other ethnic identities. Rather, Jim 
seems to juxtapose Irish and German as opposite to Japanese in relation to drinking. In doing so, Jim invokes additional stereotypes and offers these as a sarcastic/humorous rationale for why Mark's original stereotype of Dave is true.

The remark by Jim is followed by laughter from Matt and Jim. Laughter often constitutes a passive response, and may be passive here to the extent that it is not directly in alignment; however, the laughter is fairly boisterous and unequivocally positive, indicating that laughter may sometimes be more active. Mark and Dave then engage in an active neutral response by speaking to each other in an extended nonsensical sequence. Mark's Japanese consists of typical phrases one would learn in a class such as "good evening," "I'm sorry," and "how are you?" Dave's German utterances in response to Mark include something like "what is that" or "what is it" and an insult like "stupid head."10 Casey makes a passive neutral response to Jim's comment by not saying anything.

Responses to Jim's communicated stereotypes frame them overall as acceptable, humorous, and true. In addition to invoking its own stereotypes which garners its own responses, Jim's utterance can also be viewed as a response to Mark's original stereotype. Because it invokes stereotypes in a humorous way to provide a joking extension to the original stereotype, it fits into the playing around response type. Unlike what could be identified through study one, the extended view of a single conversation exposes how responses to stereotypes can build upon each other, adding credibility to communicated stereotypes. After Dave and Mark go back and forth in German and Japanese another potential stereotype surfaces.

\#3

OM: $[(($ laughs $))]$ are you speakin German at him and he's speakin Japanese at you

Mark: 'yeah॰

OM: `you people are crazy॰

$(0.8)$

$\mid{ }^{10}$ The Japanese and German utterances are spelled as they were pronounced ${ }_{\checkmark}^{11}$ It is not the intent or the ability of this study to speak to the frequency with which any single response type emerges in the data. Rather the goal is to identify emergent response types to create a preliminary taxonomy of responses that has not been discussed in prior research, and to examine how people actually respond to stereotypes. 
Dave: ((laughs)) yeah (.) a Mexican speaking Japanese (.) and a Japanese speaking German

JR names what Mark and Dave have been doing, identifying it as “crazy.” Dave's response explains the cause of the "crazy" as due to the unexpected identities of the people speaking each language. Dave labels Mark "a Mexican” and himself "a Japanese," indicating that for the former to speak Japanese and the latter to speak German is what is "crazy." This, by contrast, implies that one would expect the already-known identity of a person to match the language they are speaking: a Japanese person should speak Japanese, and a Mexican person should speak Spanish. Furthermore the stereotypical expectation is so strongly associated that a violation can be called "crazy."

The attention JR draws to this unexpected language choice and Dave's confirmation that he is a Japanese speaking the German language suggests that Dave's earlier German utterances may have been a (quite indirect) form of disagreement with Mark's claims from example \#1 that Dave's identity could only be Japanese (not German/Irish). This disagreement adds credibility to distance his Japanese identity from the imposed characteristic “can’t drink.” By doing something not expected of his category, Dave could have been, in a subtle way, asserting that he poses an exception or that associations between his ethnicity and various characteristics such as speaking Japanese and not being able to hold his liquor were unwarranted.

By disagreeing in this way, Dave does a personal defense, offering himself as an exception to the stereotype related to language expectations based on ethnicity and, even more subtly, the expectation that Japanese people can't drink. In a personal defense response, as in this case, the defense simultaneously validates the stereotype. Dave accedes that the language-person pairings were “crazy," validating generalizations as reasonable and suggesting ones made of him could have been also. Even as Dave claims exception to the stereotype (or stereotypes), he and others in the conversation demonstrate tolerance for the stereotypes communicated. The next conversation provides 
another example in which participants categorize selves and present others.

\section{\#4}

JR: o $\uparrow$ oh (0.5) Mc[Donalds

Christa: $\quad$.hh o:: $\mathrm{ah}=$

Jill: $=$ evil

(1.5)

Christa: it's pretty good actually (.) their sweet tea?

JR: a ah

Jill: ((small cough))

(1.0)

Jill: you're so like Mexican

(0.5)

JR: .HH

Jill: kay

JR: ((laughs))

In this example (three parts of which will be discussed), Jill categorizes Christa as "Mexican" with the mitigation "like" (perhaps mitigating the categorization itself—she's "sort of Mexican" or "like a Mexican" — or mitigating the seriousness of the association/stereotype). This attribution is introduced with "so," implying a matter of emphasis or degree. The comment is made directly after Christa's description of her drink being sweet tea. By labeling Christa in response to this, an association is made between "drinking sweet tea" and "being Mexican." This suggests a potential stereotype that implies all Mexican people drink sweet tea or that sweet tea is primarily enjoyed by Mexican people. The sharp in-breath, Jill's emphasis of her point (“kay,” a shortened form of “okay”), and the ensuing laughter suggest this was interpreted as funny, awkward, or some combination of both. Coupled, however, with the laugh offered by JR, it suggests a passive approval of the stereotype by both. Christa's next turn indicates disagreement, but with the particular stereotype, not with stereotyping in general.

\#5 Christa: Mexicans don't drink tea (.) [they drink Jill: [they drink] sweet tea

Christa: othey drink beero

Jill: [you know-

Christa: [( ) $\quad]^{\circ}\left(I^{\prime} m\right)$ southern ${ }^{\circ}$ 
Christa answers Jill's association by making her own: she associates the category "Mexicans" with "drink beer." She starts off saying "Mexicans don't drink tea" which begins by sounding like an accuracy discussion response type. Jill's response contributes to this interpretation, as she specifies “sweet tea." However, Christa follows with a new stereotype, "they drink beer." Here we have a subtle instance of what may be dueling stereotypes. Christa then offers a re-categorization of herself as "southern," possibly a claim against being called "Mexican," or a reason for drinking sweet tea, or both. In either case, her southern-ness is offered as a response to the conflicting assertions related to Mexicans drinking beer or sweet tea. It acts as a trump card to settle the conflict between her and Jill over whether Mexicans drink beer and sweet tea. The re-categorization also saves Christa's face, distancing her from being associated with an apparently-undesirable stereotype in favor of one which is apparently more desirable and, importantly, self-selected. Christa offers this re-categorization of herself as an alternate explanation for Jill's assertion that Mexicans—as does Christa—drink sweet tea. In doing so, Christa undermines Jill's argument, and has a subtle 'win' in the stereotype duel. In the next instance Jill and JR pick up on Christa's reformulation of what "Mexicans drink" (beer) and make a joke of it.

\#6

Jill: a:ll they drink is beer (0.5) In the morni:ng=

JR: =when they read the morning ne(h)wspaper=

Jill: =They don't rea:d

Christa: ${ }^{\circ}$ didn't say that ${ }^{\circ}$

(0.5)

Jill: All of the commercials I've seen for the sweet tea (.) all of them the ads have been in Spanish= Christa: =I don't think- everything's in Spanish

Jill repeats Christa's earlier argument that Mexicans drink beer but adds the word "all" to emphasize the unreasonableness of Christa's position. This repeating of Christa's earlier statement acts as a form of challenge, and Jill waits briefly for a response. To push for the response further, Jill does 
an amicable clarification, specifying "in the morning" as if to clarify "even in the morning they drink beer?" Rather than directly disagreeing with Christa's claim that Mexicans drink beer, or engaging in an accuracy discussion, Jill suggests the extreme form of Christa's position is unlikely. Noticeably this is based not only on the stereotype that all Mexicans drink beer, but on the implication that if Mexicans drink beer they cannot drink anything else. Jill emphasizes this with her comment "all they drink is beer."

Unlike the one-dimensional view of the response types in study one, this study enables the complexity of responses to emerge more multi-dimensionally. Simultaneously as Jill is engaging in an amicable clarification response to Christa, JR contributes another layer by adding that beer would even be consumed while reading a newspaper. This teasing constitutes a different response strategy, playing around. Jill's follow-up "they can't read" demonstrates that Jill has momentarily joined in JR's teasing response strategy. Based on her mock-serious tone of voice, it does not seem as if Jill is providing an actual stereotype, but pointing out Christa's stereotype as laughable. Simultaneously, it could also be saving face for Jill: indicating Christa's association (Mexicans=drink beer) is negative/ridiculous implies other potential negative traits (such as not being able to read), by comparison making Jill's initial stereotype (Mexicans=drink sweet tea) seem more innocuous. Thus, the response here uses stereotypes to make the Christa's association seem unwarranted, but not in a serious way. That Jill is face-saving is further supported when she provides an account for her original categorization (Christa as "Mexican" for drinking sweet tea). Jill's amicable clarification response, rather than her playing around response, is taken up once again when she mobilizes another association (that Mexican people speak Spanish) and says the commercials she has seen for the sweet tea were in Spanish. This facesaving move suggests her association was based on evidence and that, if she said something wrong, it was an honest mistake.

The simultaneous pursuit of an amicable clarification response and a playing around response 
with JR is informative about the way responses to stereotypes operate multi-dimensionally. At one level there is teasing; at another there is concern and a desire for clarification. In study one, response types were discussed as distinct and separate from each other. In study two, the data demonstrate that conversational participants are adept at managing multiple response types with each other. The next example is a clearer instance in which a stereotype is responded to with joking, and displays stereotypes about non-present particular and general others (rather than selves or present others).

\#7 Christa: We could sell them at a yard sale (1.8) at the flea market you know Mexicans love that ki- oh(3.0) Val: No comment (.) r[(acist ass)]

Christa: [rewind ] (3.0) du:de

Val: My boyfriend doesn't own a globe shut up

Chris: ((laughs)) but if you made him one I'm sure he'd love it

(1.0)

Val: I don't think so

(3.0)

Christa: What would he say if you handed him a paper mache globe.

(2.0)

Val: "I don't know what ees"

((laughter))

Val: "looks like shit"

Christa: No he'd probably jus say "o:h thank you"

Val: "Oh, thanks bayby" (1.0) "I lofe it" ((laughs)) "what the hell is it"

In this conversation between the same woman as in the last few examples (Christa) and a different friend (Valerie), Christa starts to associate the category "Mexican" with loving flea markets and the kinds of things sold there. She doesn't finish saying this, but her initial syllable "ki-“ sounds like it is projecting "kind" as in "kind of stuff." This example most strongly indicates that the association is a stereotype and a negative one, as Christa repairs mid-utterance and identifies wanting to "take it back" (by saying "rewind"- perhaps also a comment on the ongoing recording). This turn acknowledges the reproachable action and may accept some responsibility, but does not do so explicitly enough to constitute a direct account (Tracy \& Robles, 2013). Moreover, Val's “no comment" (and subsequent, possible counter-insult) shows some disapproval. The strength of this 
disapproval, however, is difficult to assign, and indicative of the weakness of this particular datum. It is not confirmable whether Val actually says "racist ass." If she does, it sounds quite strong-like an outright face-threat — though its light tone, Christa's lack of apology or indication of hurt, and the subsequent joking suggest otherwise.

Val's initial response transitions into a personal defense: she states that her (apparently Mexican) boyfriend, who doesn't own a globe, would not like that sort of thing which Christa earlier stated they could sell at the flea market, indicating that he would not even know what it was if given one. Val saves the face of her non-present boyfriend in a way which also protects the face of Christa by not constituting a strong disapproval: she imitates her boyfriend's responses with a mock Spanish accent, mitigating their seriousness. This joking indicates the playing around response type. Val's responses demonstrate how a response can evolve across utterances.

The next example features "race" as an explicit topic, and stereotypes are thus particularly relevant and salient.

\#8

Sean: but if there's like-(.) there's like two people trying to get a job a white and a black guy like the black guy would get it if they have like almost equal qualifications

Jen: >yeah $<$

Sean: just because he's black

Jen: $\mathrm{mh}:: \mathrm{m}$

Sean: even though he's gonna do the worst job=>because he's black $<$

Arden: WHA:::::::T? ((laughs))

Sean: I mean most of the time- honestly they do a worse job

(3.0)

Jen: can I have the statistics to prove that please (1.5) can I have like some (2.0) val[id sources

Sean: [it's] Sean statistics

Jen: that's not that's not a reliable? ( ) sources:o-

Sean: if you looked it up (1.0) I betcha- I betcha it's true

Arden: I don't think they [have-]

Jen: [yeah ] on what] the KKK DOT NET? like [real::ly

Arden: [((laughs)) ] [((laughs))

Sean: $>$ no, no, no $<$ that's racist I'm not racist

In this example, "black" is associated with doing "the worst job." Sean's utterances, and his interlocutors' responses to them, indicate a stereotype was communicated. Arden's response 
"WHAT?" is a challenge, taken up by Sean's "I mean. .." wherein he re-emphasizes his point. Sean's use of "most of the time" may indicate that he registered Arden's challenge and is mitigating the stereotype. Arden's awkward laughter after his challenge serves as a passive disapproval, further indicating the need for Sean to be accountable for his behavior. Jen's demand for statistics/sources (evidence for Sean's stance) serve a similar function to Arden's "What?" by also calling Sean to account. However, in contrast to Arden's open-ended response, Jen's response calls into question the accuracy of Sean's statement and the validity of his sources. Throughout, Sean's accounts for his position deny full responsibility (insisting that his opinion is based on something true even if he cannot verify it), constituting a form of excuse: he is merely repeating "facts" (Tracy \& Robles, 2013).

These responses indicate an accuracy discussion response: the truth of the stereotype and the legitimacy of evidence are repeatedly questioned to the point that Sean is prompted to distinguish what he has said from the sort of thing racists (like the KKK) would say. In making this distinction Sean provides a justification (Tracy \& Robles, 2013), saving his face by minimizing the wrongness of what he said and contrasting it with "racism." One interesting aspect of this exchange is that the communication of the stereotype associating "black people" with the activity "poor performing at work" is not itself directly challenged. Rather, Sean's explicit naming and claiming of his knowledge of this stereotype is discussed.

\section{Discussion}

These analyses indicate that response types produced in the first study may be usable to gloss participants' actions turn-by-turn as well as potentially to characterize the overall collaborative response. Embedding certain responses in the context of interaction allows us to see how the meaning of a stereotype can change across an interaction managed among multiple participants, as well as how participants use different types of response to accomplish different conversational goals. Attending to subsequent or third-position responses to stereotypes is important in making an assessment of uptake. 
Whether a participant "ignored" or "approved" a stereotype may be indicated by how the stereotyper does or does not account for what was said in the first place. This insight into the back-and-forth situation in which stereotypes occur sheds light on ways participants can effectively "get away with" producing stereotypes, and thus how stereotypes may be maintained among and about intercultural differences.

Considered alongside study one, study two provides an in-depth look at the contexts in which stereotypes are communicated and reveals some of the complexities involved when conversational partners respond to stereotypes in the moments when they are communicated. Such difficulties pose challenges to the assumptions of how stereotypes should be responded to, and suggest the specific ways in which stereotypes may be functionally maintained-despite conversants' best intentions. These particular discursive practices which maintain stereotypes also suggest how barriers to intercultural communication may emerge out of ordinary conversation.

\section{Limitations}

While study one had variation in relationships, study two overwhelmingly occurred in conversations among friends, which poses constraints when interpreting results. Stereotypes may be communicated and responded to differently depending on whether participants are friends, family, or coworkers, and whether one is treated as higher-or-lower status. As van Dijk (1992) notes, one's position affects how they may participate in racist discourse, and the implications of being associated with racist discourse also affects how one's face is displayed in that interaction. This link to face is consequential because stereotype construction happens in the talk regardless of what anyone in the conversation might think of the stereotyper, the stereotype content, its communication, and political correctness broadly.

\section{Overall Reflection and Discussion on Both Studies}

The first study provided breadth in categorizing the types of responses people use and the 
second study provided depth in exposing the multidimensionality of the ways in which these responses are used in conversation. Thus, results of study two extended the discussion from study one. Together, both studies highlight specific considerations for understanding how people respond to interpersonally communicated stereotypes and suggest some implications for intercultural communication.

First, the second study applied the emergent categorization to naturally-occurring conversational data. In contrast to an over-all response as might be prescribed by political correctness - abject disapproval of stereotypes — study one produced 13 response types. These types provide language through which responses to stereotypes can be identified and unpacked for further analysis as demonstrated in study two. Contextualizing stereotypes in the ongoing flow of talk served as a form of a member-check: the contextualization confirmed study one's interpretation of these response types as functional descriptors. The reciprocation response was the only type for which no example could be found in the conversational data.

Second, study two demonstrated the multidimensionality and fluidity of responses to stereotypes by showing how participants can have different responses in the same conversation and can change their responses over a single conversation. That people's responses to interpersonally communicated stereotypes are dynamic and interactional is not in itself news. But precisely how this process unfolds has been largely neglected in the literature. The practices by which conversational partners are able to moment-by-moment fluidly manage their responses, even when contradicting each other's, offers an in-the-field glimpse into the situations in which people actually have to contend with stereotypes.

Third, study one argued that each response type demonstrated a tolerance or intolerance of the stereotype or the communication of the stereotype. Study two demonstrates how this tolerance or intolerance is interpretable through interaction. Previous research has demonstrated that stereotypes are collaborative and based on shared meanings (e.g., Ladegaard \& Fai Cheng, 2014; Lyons \& Kashima, 
2003). But in combination, the current studies show how collaborative meanings emerge through conversations in which tolerance or intolerance for stereotypes is communicated in naturally-occurring interaction. That meaning is managed interactionally by conversational partners and may even strengthen impressions of stereotype communication as tolerable or intolerable, as it was a result of the group working together (rather than an individual alone). Responses, then, can build upon each other to lend credibility to the responses communicated earlier in the conversation and to reinforce stereotypes as acceptable or not to think or communicate. This may reinforce participant beliefs and practices which serve as barriers to intercultural understanding and communication.

This project's methods posed some limitations. Study one offered insights into how a particular population might reconstruct their responses to stereotypes experienced in conversation, illustrating a variety of discrete response types available ${ }^{11}$ to allow stereotypes maintenance. However, this provides a rather one-dimensional perspective, suggesting participants only select one sort of response. Study two balances study one with a more multi-dimensional approach which tracks stereotypes "in action" and examines response evolution over turns in a conversation, unpacking the levels of complexity in which people respond to interpersonally communicated stereotypes. Taken together in a multimethodological approach, then, each study balances some of the other's weaknesses — providing breadth in the case of the former and depth in the latter.

Because non-tolerant responses potentially violate social norms for civil inattention, responses to responses are an important component of understanding whether and how communicated stereotypes are constructed as problematic and a topic for further investigation in future research. Future research could incorporate sequences of responses into qualitative coding and further examine responses to responses to communicated stereotypes, as well as exploring these phenomena among

\footnotetext{
${ }^{11}$ It is not the intent or the ability of this study to speak to the frequency with which any single response type emerges in the data. Rather the goal is to identify emergent response types to create a preliminary taxonomy of responses that has not been discussed in prior research, and to examine how people actually respond to stereotypes.
} 
other populations.

Stereotype maintenance research examines reproductions of stereotypic knowledge over time through communication processes (e.g., Lyons \& Kashima, 2001; Schaller, Conway, \& Tanchuk, 2002). Despite societal prescriptions to the contrary, our studies found that responses to stereotypes may facilitate the perpetuation of stereotypes and stereotype maintenance by demonstrating tolerance for thinking or communicating stereotypes. If responses demonstrate tolerance for the stereotype or its communication, then the person responding may be perceived as being tolerant of thinking or communicating stereotypes. These results suggest that intercultural communication research should attend to the use of stereotypes in conversational data to understand how intercultural perceptions are constructed interactionally, as well as how stereotypes about "other" groups are managed in everyday life, and the implications of these cultural constructions. 


\section{References}

Baumeister, R. F., Wotman, S. R., \& Stillwell, A. M. (1993). Unrequited love: On heartbreak, anger, guilt, scriptlessness, and humiliation. Journal of Personality and Social Psychology, 64, 377394.

Bodenhausen, G. V., \& Macrae, C. N. (1996). The self-regulation of intergroup perception: Mechanisms and consequences of stereotype suppression. In C. N. Macrae, C. Stangor, \& M. Hewstone (Eds.), Stereotypes and stereotyping (pp. 227-253). NY: Guilford Press.

Borisoff, D., \& Victor, D. A. (1989). Conflict management: A communication skills approach. Englewood Cliffs, NJ: Prentice Hall.

Boyatzis, R.E. (1998). Transforming qualitative information: Thematic analysis \& code development. Thousand Oaks, CA: Sage.

Buttny, R. (1993). Social accountability in communication. London: Sage.

Carlin, A. (2010). Discussion note: Reading ‘a tutorial on membership categorization’ by Emanuel Schegloff. Journal of Pragmatics, 42, 257-261.

Coffey, A., \& Atkinson, P. (1996). Making sense of qualitative data: Complementary research strategies. London: Sage.

Condor, S. (2006). Public prejudice as collaborative accomplishment: Towards a dialogic social psychology of racism. Journal of Community and Applied Social Psychology, 16, 1-18.

Dougherty, D. S. (2001). Women's discursive construction of a sexual harassment paradox. Qualitative Research Reports, 2,1, 6-13.

Edwards, D. (2005). Discursive psychology. In K. L. Fitch \& R. E. Sanders (Eds.), Handbook of language and social interaction (pp. 257-273). Mahwah, NJ: Erlbaum.

Elgin, P. \& Hester, S. (2003). The Montreal massacre: A story of membership categorization analysis. Waterloo, Ontario: Wilfrid Laurier Press. 
Gilbert, G. M. (1951). Stereotype persistence and change among college students. Journal of Abnormal and Social Psychology, 46, 245-254.

Glaser, B. G., \& Strauss, A. L. (1967). The discovery of grounded theory: Strategies for qualitative research. NY: Aldine Atherton.

Goffman, E. (1959). The presentation of self in everyday life. NY: Anchor Books.

Goffman, E. (1963a). Behavior in public places. NY: Free Press.

Goffman, E. (1963b). Stigma: Notes on the management of spoiled identity. NY: Simon \& Schuster.

Hakansson, J. \& Montgomery, H. (2003). Empathy as an interpersonal phenomenon Journal of Social and Personal Relationships, 20, 267-284.

Haslam, S. A., Turner, J. C., Oakes, P. J., Reynolds, K. J., \& Doosje, B. (2002). From personal pictures in the head to collective tools in the world: How shared stereotypes allow groups to represent and change social reality. In C. McGarty, V. Y. Yzerbyt, \& R. Spears, (Eds.), Stereotypes as explanations: The formation of meaningful beliefs about social groups (pp. 157-185). Cambridge: University Press.

Jussim, L. J., McCauley, C. R., \& Lee, Y. (1995). Why study stereotype accuracy and inaccuracy? In Y. Lee, L. Jussim, \& C. McCauley (Eds.), Stereotype accuracy: Toward appreciating group differences (pp. 3-27). Washington, DC: American Psychological Association.

Karlins, M., Coffman, T. L., \& Walters, G. (1969). On the fading of social stereotypes: Studies in three generations of college students. Journal of Personality and Social Psychology, 13, 1-16.

Katz, D., \& Braly, K. W. (1933). Racial stereotypes of one hundred college students. Journal of Abnormal Social Psychology, 28, 280-290.

Kenrick, D. T., Maner, J. K., Butner, J., Li, N. P., Becherk, D. V., \& Schaller, M. (2002). Dynamical evolutionary psychology: Mapping the domains of the New Interactionist Paradigm. Personality and Social Psychology Review, 6, 347-356. 
Koenig Kellas, J., \& Manusov, V. (2003). What's in a story? The influence of narrative completeness on tellers' adjustment to relationship dissolution. Journal of Personal and Social Relationships, 20, 285-308.

Kurylo, A. (2012). What are they like? Non-expert definitions of stereotypes and their implications for stereotype maintenance, Qualitative Research in Psychology, 9, 337-350.

Kurylo, A. (2013). The communicated stereotype: From celebrity vilification to everyday talk. Lanham, MD: Lexington Books.

Ladegaard, H. J. \& Fai Cheng, H. (2014). Constructing the cultural 'other': Prejudice and intergroup conflict in university students' discourse about 'the other.' Language and Intercultural Communication, 14, 156-175.

Lindlof, T. R. \& Taylor, B. C. (2011). Qualitative communication research methods( $3^{\text {rd }}$ ed.). Los Angeles, CA: Sage.

Lippmann, W. (1922/1965). Public opinion. NY: Free Press.

Lyons, A., \& Kashima, Y. (2001). The reproduction of culture: Communication processes tend to maintain cultural stereotypes. Social Cognition, 19, 372-394.

Lyons, A., \& Kashima, Y. (2003). How are stereotypes maintained through communication? The influence of stereotype sharedness. Journal of Personality and Social Psychology, 85, 9891005.

Madon, S., Jussim, L., Keiper, S., Eccles, J., Smith, A., \& Palumbo, P. (1998). The accuracy and power of sex, social class and ethnic stereotypes: A naturalistic study in person perception. Personality and Social Psychology Bulletin, 24, 1304-1318.

Mertins, J. \& Baus, R. (2010). A stages of change approach to second language learning and intercultural willingness to communicate. Journal of Intercultural Communication Research, $39,13-28$. 
Orbe, M. P., \& Warren, K. T. (2000). Different standpoints, different realities: Race, gender, and perceptions of intercultural conflict. Qualitative Research Reports, 1, 3, 51-57.

Ottati, V., \& Lee, Y. (1996). Accuracy: A neglected component of stereotype research. In Y. Lee, L. Jussim, \& C. McCauley (Eds.), Stereotype accuracy: Toward appreciating group differences (pp. 29-59). Washington, DC: American Psychological Association.

Ramasubramanian, S. (2010). Testing the cognitive-affective consistency model of intercultural attitudes: Do stereotypical perceptions influence prejudicial feelings? Journal of Intercultural Communication Research, 39, 105-121.

Ramasubramanian, S. (2011). The impact of stereotypical versus counterstereotypical media exemplars on racial attitudes, causal attributions, and support for affirmative action. Communication Research, 38, 497-516.

Rees, N. (1993). The politically correct phrasebook. What they say you can and cannot say in the 1990’s. London: Bloomsbury.

Rule, B. G., Bisanz, G. L., \& Kohn, M. (1985). Anatomy of persuasion schema: Targets, goals, and strategies. Journal of Personality and Social Psychology, 48, 1127-1140.

Sacks, H. (1972). On the analyzability of stories by children. In J. J. Gumperz \& D. Hymes (Eds.), Directions in sociolinguistics: The ethnography of communication (pp. 325-345). New York: Holt, Rinehart and Watson.

Sacks, H. (1992). Lectures on conversation. Cambridge, MA: Blackwell.

Sacks, H. \& Schegloff, E. A. (1979). Two preferences in the organization of reference to persons and their interaction. In G. Psathas (Ed.), Everyday language: Studies in ethnomethodology (pp. 1521). New York: Irvington Publishers.

Schaller, M. \& Latané, B. (1996). Dynamic social impact and the evolution of social representations: A natural history of stereotypes. Journal of Communication, 46, 64-77. 
Schaller, M., Conway, III, L. G., \& Tanchuk, T. L. (2002). Selective pressures on the once and future contents of ethnic stereotypes: Effects of the communicability of traits. Journal of Personality and Social Psychology, 82, 861-877.

Semin, G. R. (2000). Agenda 2000-Communication: Language as an implementational device for cognition. European Journal of Social Psychology, 30, 595-612.

Strauss, A., \& Corbin, J. (1998). Basics of qualitative research: Techniques and procedures for developing grounded theory. London: Sage.

Thibodaux, D. (1994). Beyond political correctness: Are there limits to this lunacy? Lafayette, LA: Huntington House Publishers.

Ting-Toomey, S. (2007). Intercultural conflict training: Theory-practice approaches and research challenges. Journal of Intercultural Communication Research, 36, 255-271.

Tracy \& Robles, 2013

van Dijk, T. (1992). Discourse and the denial of racism. Discourse \& Society, 3, 87-118.

Watson, R. (1997). Some general reflections on 'categorization' and 'sequence' in the analysis of conversation. In S. Hester \& P. Eglin (Eds.), Culture in action: Studies in membership categorization analysis (pp. 49-75). Washington, DC: University Press of America.

Williams, J. (1995). PC wars: Politics and theory in the academy. New York: Routledge.

Wright, K., (2000). The communication of social support within an on-line community for older adults: A qualitative analysis of the senior net community. Qualitative Research Reports, 1, 3, $33-43$. 
Appendix A

Response types

\begin{tabular}{|l|c|c|}
\hline \multicolumn{2}{|c|}{ Passive } & Active \\
\hline Neutral & Passive Neutral & Active Neutral \\
\hline Approval & Passive Approval & Active Approval \\
& Amicable clarification & \\
& Playing Around & \\
\hline Disapproval & Dueling Stereotype & Active Disapproval \\
& Reciprocation & Challenge $^{12}$ \\
& Passive Disapproval & Personal Defense \\
& & Accuracy Discussion \\
& & \\
\hline
\end{tabular}

\footnotetext{
${ }^{12}$ Without additional response.

${ }^{13}$ With or without challenge.

${ }^{14}$ With or without challenge.
} 